Readability of annual reports of firms listed in Egyptian Exchange

Dr. Mohsen Ebied Abdelghafar Younis

Faculty of Commerce - Menoufia University 


\title{
Readability of annual reports of firms listed in Egyptian Exchange
}

\author{
Dr. Mohsen Ebied Abdelghafar Younis ${ }^{1}$ \\ Faculty of Commerce - Menoufia University
}

\begin{abstract}
The research aims to examine two fold objectives. First, it measures the readability of chairman's letter and social responsibility textual report throughout financial and non-financial firms in Egypt. Second, it describes the relationship among extant techniques of readability in accounting literature. The research utilizes exclusively five techniques in order to analyze narrative disclosure regarding prior paragraphs of annual reports. Unlike prior literature, the research analyzes the textual content using comprehensive set of measures which are Flesch reading ease, Gunning fog, Flesch-Kincaid grade, SMOG grade, Dale-Chall score. The results reveal that there is no significant difference between financial and non-financial Egyptian firms concerning the theme of readability of annual reports. Whereas the relationship between Flesch reading ease and other extant measures of readability is negative and significant. The research provides practical implications to shareholders, stakeholders, investors, financial analysts and other interested parties as they will be better able to detect the managerial obfuscation and understand easily the content of narrative annual reports.
\end{abstract}

Keywords: Readability formulas; social responsibility; narrative disclosure; Egypt.

${ }^{1}$ Lecturer in accounting department. 


\section{Introduction}

Annual reports of the firm are the main tool to convey information to interested parties (e.g., shareholders, investors, creditors, suppliers, customers, governmental agencies and employees' unions) in order to rational their decisions concerning that firm. Moreover, annual reports include qualitative information such as narrative disclosure information (e.g., chairman's letter, corporate social responsibility report, auditors' report, footnotes and investors' relations) and quantitative information such as financial statements. Generally, readability of annual reports plays main role in the maintenance of quality relatively related to effective communication.

The issue of readability of annual reports has received considerable critical attention in financial reporting and disclosure since prevalence of the hypothesis of managerial obfuscation. Subsequently, managers act intentionally to overcast information or footnotes when the firm performance is poor and in this case the annual reports are difficult to read. Conversely, the management of the firm with flourish performance is willing to be more forthcoming concerning disclosure of information ( $\mathrm{Li}, 2008)$.

Narrative disclosure of financial and non-financial information is subjected to scan in order to investigate the existence of thematic and syntactic characteristics. Thus, it is originally ease to explore the content and readability of the message (Jones, 1994). An example of this is the study carried out by Jones (1988) that investigated the readability of chairman's narratives using Flesch reading ease score. In same line, Barnett and Leoffler (1979) examined the readability of accounting and auditing messages using the prior measure .

In addition, Linsley and Lawrence (2006) measured the level of readability of risk disclosure in UK firms depending on Flesch reading ease score. In contrast, seminal work by Taylor (1953) measured readability throughout cloze procedure which is psychological tool to measure effective written communication. Recently, Cheung and Lau (2016) examined the readability of financial disclosure especially after adoption of IFRS in Australian context using fog index .To conclude, prior accounting research utilized individually different measures in order to determine the level of readability of narrative and financial disclosure.

One criticism of much of the literature on readability of narrative disclosure is that depending on a single measure .Unlike prior research, the current study uses five measures of readability of annual reports besides describes the relationship between these measures. The key problem of research with this explanation is to determine whether there is significant difference between financial and non-financial firms concerning readability of narrative disclosure and to explain carefully the relationship between measures of readability that known in extant accounting literature.

In addition, no research has been found that gathers measures of readability of narrative disclosure regarding president statement and social responsibility report in order to evaluate the levels of readability and explore the relationship between these measures, to the best of knowledge the study is the first to examine the readability of chairman's letter and social responsibility disclosure especially in Egypt with five measures together and the study tends to cover this gap in accounting literature. 
This research seeks to address the following questions. First, whether there is a significant difference between financial firms and non-financial firms regarding the levels of readability of narrative disclosure especially that related to chairman's letter and social responsibility. Second, whether there is a significant relationship among extant techniques of readability in accounting literature.

The remainder of the research is structured as follows. The second section illustrates literature review of readability and hypotheses development. The third section discusses the research design. The fourth section reports the empirical results where conclusions are drawn in the fifth section.

\section{Literature review and hypotheses development}

\subsection{Readability measures}

A large and growing body of accounting literature has investigated readability of annual reports within developed countries especially UK (e.g., Jones, 1988 ; Smith and Taffler, 1992;Jones,1996;Courtis,1995 ;Courtis,1998;Clatworthy and Jones,2001 ;Linsley and Lawrence,2007), USA (e.g., Poshalian and Crissy,1952 ; Schroeder and Gibson, 1992 ;Subramanian et al, 1993 ;Li, 2008 ; Moffitt and Burns, 2009 ;Lehavy et al ,2011 ; Sattari et al ,2011 ;Lo et al ,2017), Canada (e.g.,Courtis, 1986), Australia (e.g.,Hrasky and Smith , 2008 ; Cheung and Lau , 2016), New Zealand (e.g., Richards and Staden, 2015). However, slight grasp of research examined the notion of readability in Asian countries especially China, Malaysia and Hong Kong (e.g., Courtis and Hassan, 2002; Rahman , 2014). Until recently, there has been no reliable evidence of discussing the theme of readability of annual reports in emerging countries especially in Middle East. Accordingly, the major objective of the research is to cover this gap in Egypt.

Stream of accounting research has been concentrated on measuring the readability of annual reports using Flesch reading ease individually .In this context, the results revealed that readability of annual reports were closely difficult (Poshalian and Crissy , 1952 ; Jones, 1988 ; Courtis and Hassan, 2002; Hrasky and Smith ,2008 ; Rahman, 2014). Earlier studies e.g., Burnett and Loeffler (1979) measured the readability of accounting and auditing messages using Flesch reading ease.

Likewise, Courtis (1998) examined the readability of chairman's address sections of 120 public companies in Hong Kong Stock Exchange throughout the period 1994-1995. The results concluded that the variability of readability is prevalent in the sample. Cash and Tsai (2017) uses Flesch reading ease in order to measure the readability of credit card arrangements.

In contrast, another stream has been employed additional measures otherwise Flesch reading ease in order to determine the readability of annual reports. In particular, the supportive readability formulas were Dale-Chall, Fog index(e.g., Courtis,1986; Subramanian et al,1993; Li ,2008; Lehavy et al ,2011; Lo et al , 2017), Flesch-Kincaid (e.g, Schroeder and Gibson, 1992; Subramanian et al, 1993; Sattari et al , 2011), Close procedure and Lix measure (e.g, Smith and Taffler, 1992), SMOG index and count of passive sentences (e.g., Schroeder and Gibson, 1992; Hrasky and Smith , 2008;Cash and Tsai , 2017). 
Particularly, Flory et al (1992) measured the readability of accounting textbooks based on two measure of readability which are Flesch reading ease formula and Gunning's Fog Index .Typically, results reveal that divergence across textbooks were insignificant.Additionally, $\mathrm{Li}$ (2008) investigated the management obfuscation hypothesis throughout the fog index and earnings persistence. The results revealed that firms with poor financial performance have higher fog index. Thus, their annual reports are more complicated to read. In the same line, Lo et al (2017) employed the fog index in order to determine the readability of annual reports and its relation with earnings management.

Unlike, Bonsall et al, (2017) measured the readability of financial reporting using bog index as a plain English measure. Generally, Kumar (2014) examined the key determinants (e.g., secrecy, ownership structure and profitability) of readability of annual reports of 68 Asian firms that listed in US securities exchange. The results revealed that firms with higher secrecy and profitability are providing less readable annual reports and firm with higher dispersion of ownership structure are producing more readable annual reports. Additionally, Subramanian et al (1993) concluded that annual reports of confident performance were readable relatively to poor performance, Likewise, Moffitt and Burns (2009) revealed that faithful reports were easier to read than reports with fraudulent.

Debate continues about the impact of adoption of IFRS on readability measures. For example, Cheung and Lau (2016) examined the impact of IFRS adoption on financial reporting readability in the Australian context. The results concluded that financial reports are satisfactory longer and more readable in the post of IFRS adoption. Further, the length of disclosure related to summary of significant accounting policies, financial instruments and intangible assets are considerably longer after IFRS adoption. In contrast, the results that reported by Richards and Saden (2015) revealed that the adoption of IFRS has been added somewhat complexity on readability measures and resulted in declined the readability of narrative disclosure in annual reports.

The concept of readability has recently been challenged by auditing studies demonstrating to what extent auditors' reports are difficult to read. In this line, Fakhfakh (2016) scrutinized the compliance level of auditors' reports with linguistic rules and the results revealed that the footnotes of auditors' reports are not compliant with some linguistic rules. In addition Du Toit (2017) examined the readability of integrated reports and concluded that integrated reports are closely difficult to read.

More recently, the concern regarding readability has been extended to the financial accounting aspects .For example, Ajina et al, (2016) examines the relationship between annual reports and earnings management using a sample of 163 firms that listed in French stock market. The results concluded that firms which manipulate their earnings act intentionally to make annual reports readability more complicated. It is consistent with the results which have been argued by ( $\mathrm{Li}, 2008$; Bloofield, 2008).The results implied that annual reports of firms with lower earnings are longer and difficult to read.

There is increasing concern that readability formulas are being disadvantaged from several aspects. First, possibility of getting wide variations of results about specific text. Second, the readability differentiates extremely from understandability. 
Third, readability formulas merge mathematics to literature and they cannot measure the coherence of the text. However, much of the research up to now has explained the advantages of readability formulas in the following reasons. First, readability formulas determine the grade-level reader must have to read the text. Second, readability formulas are text- based measures and they easy to use.

\subsection{Hypotheses development}

Financial firms especially banks are subjected to special legislations in order to prepare their annual reports. On the other side, non-financial firms are controlled with different accounting standards. To what extent the divergence in legislation and accounting procedure affect the readability of annual reports in both categories. Subsequently, I tend to examine the conjecture related to diversity of annual reports readability in financial and non-financial firms throughout the following hypotheses:

Ha1: There is a significant difference between financial and non-financial firms regarding the readability of chairman's letter.

Ha2: There is a significant difference between financial and non-financial firms regarding the readability of social responsibility report.

A considerable amount of research has been published on the measures of readability. However, these attempts did not explain the relationship concerning different measures of readability as extant literature was limited by using one measure of readability. Unlike the prior research this study aims to examine the relationship among 5 measures of readability throughout the following hypotheses:

Ha3: There is a negative relationship between the Flesch reading ease and other extant measures of readability of chairman's letter.

Ha4: There is a negative relationship between the Flesch reading ease and other extant measures of readability of social responsibility report.

\section{Research design}

\subsection{Sample selection and data collection}

The sample comprises of annual reports of firms distributed throughout the highest sectors of Egyptian exchange during 2017.The sample is determined from three sectors which are banks, real estate and chemicals that contribute of total market cap nearly by $22.28 \%, 11.37 \%$ and $8.22 \%$ respectively. Additional criterions are considered especially availability of chairman's letter and social responsibility report in English word format. However, majority of Egyptian companies disclose their annual reports in Arabic format or English PDF format, which are unsuitable to fit with the computerized analyzer of readability. Accordingly the final sample consists of nine firms which are stratified into four financial firms by approximately $44 \%$ and five non- financial firms by nearly $66 \%$.The data is gathered from the annual reports and investor relations portion throughout the formal web-side of the firms, financial statements and its footnotes. 


\subsection{Methodology}

Unlike the prior research that based on one measure of readability, I measured the readability of narrative disclosure concerning chairman's letter and social responsibility using five measures which are Flesch reading ease, Gunning fog scale level, Flesch-Kincaid grade level, SMOG grade and Dale-Chall score. Moreover, I apply these measures individually to analyze the chairman's letter and social responsibility disclosure.

\subsection{Variables measurement}

I measured the readability of textual content regarding chairman's letter and social responsibility report based on readability intelligent analyzer. The outputs of prior technique are classified into main categories one of them presents the descriptive statistics of examined passage especially number of sentences, words per sentence, character per word and percentage of difficulty. Whereas, another one is in charge of showing the scores of readability formulas that included in previous accounting literature.

\subsection{Readability formulas}

Numerous studies have attempted to explain the formulas which are charge of measuring readability as follows:

\section{Flesch reading ease}

$=206.835-1.015\left(\frac{\text { total words }}{\text { total sentences }}\right)-84.6\left(\frac{\text { total syllables }}{\text { total words }}\right) \ldots(1)$

The prior formula measures the both average sentence length by words and the average word length by syllables. Accordingly, when the passage is difficult to read we should shorten the words and sentences until the passage be more readable. In the context, the ratio of syllables to words determines the mental work the reader has to do. Generally, the score moves between 0 and 100.Zero refers that the text is virtually unreadable and 100 means that it's tremendously easy.

$\underline{\text { Flesch-Kincaid grade level }}$

$=0.39\left(\frac{\text { total words }}{\text { total sentences }}\right)+11.8\left(\frac{\text { total syllables }}{\text { total words }}\right)-15.59$

Current formula is based on word length and sentence length likewise the Flesch reading ease, but they have different weighting factors. Specifically, the outputs of these tests are related almost inversely. Comparatively, a text with low score on the Flesch reading ease test should have a higher score on the Flesch-Kincaid grade level test and vice versa.Moreover, the output of the test is a figure that refers to a U.S. grade level.

Gunning fog index

$=0.4\left[\left(\frac{\text { words }}{\text { sentences }}\right)+100\left(\frac{\text { complex words }}{\text { words }}\right)\right] \ldots(3)$

Increasingly, this index aims to determine the formal education a reader needs to understand the text throughout the first reading. The formula is created by Gunning in 1952. Although, the fog index is a good sign of hard-to-read text, it has some 
limitations. For instance, some words may have several syllables and due to their common use they are easy to read.

$\underline{\text { SMOG index }}$

$=1.0430 \sqrt{\text { number of polysyllables } \times\left(\frac{30}{\text { number of sentences }}\right)}+3.1291 \ldots \ldots(4)$

A considerable amount of accounting literature has been published on SMOG index in order to determine whether the text is difficult to read. These studies referred that SMOG is an abbreviation for Simple Measure of Gobbledygook (e.g., Fakhfakh, 2016). Traditionally, SMOG index measures the educational years that a person needs to understand a bit of writing. Due to practical constraints, this index cannot determine the readability of a text which is less than 30 sentences.

$\underline{\text { Dale-Chall score }}$

$=0.1579\left(\frac{\text { difficult words }}{\text { words }} \times 100\right)+0.0496\left(\frac{\text { words }}{\text { sentences }}\right) \ldots(5)$

The aim of this formula was to provide a numeric measure of difficulty that a person meets when reading a text. Accordingly, when the score increases this means that the text has higher difficulty to read.

\section{Empirical results and discussion}

\subsection{Descriptive statistics}

Readability analyzer output include several items that describe carefully whether the examined text is fit to be readable or difficult to read. Table (1) shows the descriptive statistics of textual content of chairman's letter. Panels (A) reports the main descriptive statistics of the total sample, financial firms and non-financial firms together regarding textual content of chairman's letter. In particular, the analysis of chairman's letter is achieved throughout different aspects which are number of sentences, words per sentences, characters per word, Percent of difficult words, Flesch reading ease, Gunning fog level scale, Flesch-Kincaid grade level, SMOG grade and Dale- Chall score. Generally, the mean of prior variables is 47.1, 20.2, 5.2, 2.6, 36.1, 17.0, 13.2, 12.9 and 10.1 respectively. Moreover, the values of standard deviation of previous variables are $53.5,10.2,0.2,7.1,11.3,4.2,4.0,3.7$ and 0.7 individually. Otherwise, SMOG measure is processed with data of five cases because it requires at least text with 30 sentences.

\section{<Insert Table (1) about here>}

Panel (B) as shown in table (1) presents the descriptive statistics of variables relatively with four financial firms where the maximum number of sentences is 139.0 with mean by 83.5 and standard deviation by 65.5.In the same context, the highest number of words in the sentence is 28.00 whilst the mean and standard deviation are 12.6 and 10.7 respectively. The mean and standard deviation of Flecsh reading ease are 44.8 and 10.1 individually. It is consistent partially with the result that reported in the seminal work by Poshalian and Crissy (1952) especially sectors of merchandise and communication. Additionally the mean of other readability measures in financial 
firms especially Gunning fog, Flesch - Kincaid grade level, and SMOG grade is 13.9, 10.1 and 12.1 individually.

On another side, table (2) shows comparatively the descriptive statistics of readability measures of social responsibility narrative disclosure for financial and non-financial firms. As shown in panel (D) the SMOG measure has the smallest number of cases by 3 firms 2 of them for financial firms and the third is classified as non- financial firm because of this measure requires at least thirty sentences to work effectively.

\section{$<$ Insert Table (2) about here>}

Panel (E) reports that the mean of number of sentences related to social responsibility disclosure is 101.0 and maximum value is 318.0 sentences .Moreover, the percent of difficult words in mean is $29 \%$ and the score of Flesch reading ease is 27.7 with standard deviation by 8.0 .Otherwise, the mean of other measure of readability such as Gunning fog, Flesch - Kincaid, Dale- Chall are slighter than by approximately 17.4,12.9 and 10.7 individually. In addition, panel (F) indicates that the mean of Flesch reading ease in non-financial firms is lesser than the mean in financial firms. Potential explanation of this result is the key impact of industry on textual content of social responsibility disclosure.

\subsection{Empirical results}

As can be seen from table (3), the results of Mann-Whitney test that report the difference of readability measures of chairman's letter between financial and nonfinancial firms are differentiated widely. The results reveal that there are highly significant difference between two types especially in the number of sentences regarding the chairman's message or letter and the value of Flesch reading ease as the significance value of these prior measures are 0.01 and 0.02 respectively.

$$
\text { < Insert Table (3) about here> }
$$

Otherwise, the differences between financial and non-financial firm are insignificant concerning the length of sentences, characters per word, percent of difficult words, Gunning fog level scale, Flesch - Kincaid grade level, SMOG and Dale- Chall score because the value of significance of prior readability measures are more than 0.05 by approximately $0.08,0.46,0.46,0.08,0.08,0.048$ and 0.22 individually. Overall, prior readability measures did not affected by industry.

Concerning the readability measures which are relatively related to social responsibility disclosure, table (4) presents an overview of possible differences between the financial and non-financial firms. The results obtained from preliminary analysis of Mann-Whitney test reveal that there is no satisfactory difference between firms' types in the theme of readability measures of social responsibility disclosure because of the value of significance is greater than .05 and this refers to fully convergence between different types of firms about the readability measures of social responsibility narrative disclosure.

\section{$<$ Insert Table (4) about here>}

Table (5) presents the intercorrelations among the measures of readability of chairman's letter. It is apparent from this table that there is highly strong and significant relationship between the length of chairman's letter and the percent of difficult words as the Person correlation coefficient is $0.925^{* *}$. In addition, there is a positive, strong and significant correlation between the length of chairman's letter and Flesch reading ease measure by $0.667 *$.It means that when the chairman's message is longer, the letter became readable. Conversely, the relationship between the length of 
chairman's letter and other readability measures especially Gunning fog level scale and Flesch - Kincaid grade level is negative, strong and significant and the Person correlation coefficient of prior coefficient is $-0.759 *$ and $-0.772 *$ respectively.

< Insert Table (5) about here>

In the same context, table (6) shows an overview of correlation coefficients of readability measures concerning the social responsibility narrative disclosure. Person correlation coefficient is used in order to report the relationship among available measures of readability. The results reveal that there is highly significant, strong and positive relation between the words per sentence from one side and each of Gunning fog level scale and Flesch - Kincaid grade level and the correlation coefficients are $0.950^{* *}$ and $0.924^{* *}$.It is apparent that the relationship between Gunning fog level scale and Flesch - Kincaid grade level is $0.956^{* *}$.

< Insert Table (6) about here>

Dissimilarity, the results obtained from Person correlation coefficients refer to negative ,strong and significant relationship between Flesch reading ease and other accepted readability measures e.g., Gunning fog level, Dall- Challe score and Flesch Kincaid grade level .In particular, the correlation coefficient between Flesch reading ease and these prior measures is $-0.712^{*},-0.735^{*}$ and $-0.812^{* *}$ respectively.

\section{Conclusions}

The current research is designed to examine the key difference between financial and non-financial firms concerning the narrative disclosure readability (e.g., Chairman's letter and social responsibility passage) in Egypt. The evidence is consistent with firm's secrecy and divergence regarding disclosure level. The most observable finding to emerge from the research is that existence of significant diversity of readability measures relatively related to chairman's letter. In particular, the research finds that the Flesch reading ease and length of letter, unlike other measures, are differentiated significantly between financial and non-financial firms. In contrast, the scan of readability measures concerning social responsibility disclosure reveals that there is no satisfactory difference between financial and non-financial firms throughout all examined readability measures.

The second major finding was that clarifying the direction, significance and strength of relationship between readability measures. Specifically, the Flesch reading ease measure which used extensively the accounting literature is correlated negatively and significantly with other accepted measures of readability especially Gunning fog level scale, Flesch - Kincaid grade level and Dall- Challe score.

The findings of current research should be of interest of annual reports preparer and other related categories that use annual reports in the process of decision making especially shareholders, investors, financial analysts and stakeholders. While extant accounting research of readability based on one or two measures at maximum (e.g., Lehavy et al, 2011; Ajina et al, 2016;Taylor, 1953; Barnett and Leoffler, 1979; Cash and Tsai, 2017), this research gathers approximately nine measures of readability. This is the first study reporting comparison between several measures of readability in order to examine whether the textual content of chairman's letter and social responsibility report is readable or difficult to read in financial and non-financial firms. This work has key practical applications for financial analysts, shareholders and stakeholders in order to determine the effectiveness of written communication throughout the annual reports. Although the research is based on a small sample of 
firms, the findings suggest the need to measure the readability of narrative disclosure in order to increase the understandability of annual reports.

A limitation of this study is that the number of firms was relatively small because the annual reports of firms in Egypt are originally issued in Arabic format, while the software of data analyzer is designed basically for English format. Hence, the findings of the study need to be interpreted cautiously. Further research might investigate the readability of audit reports, corporate governance disclosure and integrated reporting. It would be interesting to compare the readability measures with large scale of countries in order to assess the impact of cultural factors on readability of annual reports. More broadly, further research is also needed to explore the economic consequences of IFRS on financial reporting readability.

\section{References}

Ajina, A., Laouiti, M. and Msolli, B.(2016),"Guiding through the Fog: Does annual report readability reveal earnings management?", Research in International Business and Finance, Vol. 38, pp.509-516.

Barnett, A. and Leoffler, K. (1979),"Readability of accounting and auditing messages", The Journal of Business Communication (1973), Vol. 16, No. 3, pp.49-59.

Bonsall , S.B., Leone, A.J., Miller, B.P. and Rennekamp , K. ( 2017)," A plain English measure of financial reporting readability, "Journal of Accounting and Economics, Vol .63, No.2, pp.329-357.

Cash, A. and Tsai, H.J. (2017)," Readability of the credit card agreements and financial charges", Finance Research Letters.

Cheung, E. and Lau, J. (2016)," Readability of Notes to the Financial Statements and the Adoption of IFRS", Australian Accounting Review, Vol.26, No.2, pp.162176.

Clatworthy, M., \& Jones, M. J. (2001)" The effect of thematic structure on the variability of annual report readability", Accounting, Auditing \& Accountability Journal, Vol.14, No.3, pp. 311-326

Courtis, J.K. (1986), "An investigation into annual report readability and corporate risk-return relationships" Accounting and Business Research, Vol. 16, No.64, pp. 285-294.

Courtis, J.K. (1995), " Readability of annual reports: Western versus Asian evidence", Accounting, Auditing \& Accountability Journal, Vol.8, No.2, pp.4-17.

Courtis, J.K.(1998)," Annual report readability variability: tests of the obfuscation hypothesis", Accounting. Auditing \& Accountability Journal, Vol.11,No.4, pp.459-472.

Courtis, J.K. and Hassan, S.(2002)"Reading ease of bilingual annual reports". The Journal of Business Communication, Vol.39, No.4, pp.394-413.

Du Toit, E. and du Toit, E. (2017),"The readability of integrated reports", Meditari Accountancy Research, Vol.25, No. (4), pp.629-653.

Flory, S.M., Phillips, T.J. and Tassin, M.F.(1992)," Measuring readability: A comparison of accounting textbooks", Journal of Accounting Education , Vol.10, No.1, pp.151-161.

Hrasky, S. and Smith, B.(2008),"Concise corporate reporting: communication or symbolism?", Corporate Communications: An International Journal, Vol. 13,No.4, pp.418-432. 
Jones, M.J., (1988)"A longitudinal study of the readability of the chairman's narratives in the corporate reports of a UK company". Accounting and Business Research, Vol.18, No.72, pp.297-305.

Jones, M.J. and Shoemaker, P.A. (1994)."Accounting narratives: A review of empirical studies of content and readability, Journal of Accounting Literature, Vol.13, p.142.

Jones, M. J. (1996)" Readability of annual reports: Western versus Asian evidence-a comment to contexualize", Accounting, Auditing \& Accountability Journal, Vol. 9,No.2, pp. 86-91

Kumar, G., (2014),"Determinants of readability of financial reports of US-listed Asian companies" Asian Journal of Finance \& Accounting, Vol .6, No.2, p.1.

Lehavy, R., Li, F. and Merkley, K.J.(2011),"The effect of annual report readability on analyst following and the properties of their earnings forecasts, The Accounting Review, Vol.86, No.3, pp.1087-1115.

Li, F., (2008)," Annual report readability, current earnings, and earnings persistence", Journal of Accounting and economics, Vol.45, No.2, pp.221-247.

Linsley, P.M. and Lawrence, M.J.(2007),"Risk reporting by the largest UK companies: readability and lack of obfuscation", Accounting, Auditing \& Accountability Journal, Vol.20 ,No.4, pp.620-627.

Lo, K., Ramos, F. and Rogo, R., (2017),"Earnings management and annual report readability", Journal of Accounting and Economics, Vol.63, No.1, pp.1-25.

Moffitt, K. and Burns, M.B.(2009)," What does that mean? Investigating obfuscation and readability cues as indicators of deception in fraudulent financial

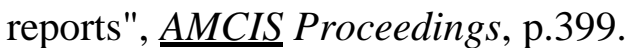

Poshalian, S. and Crissy, W.J.(1952),"Corporate annual reports are difficult, dull reading, human interest value low, survey shows", Journal of Accountancy (pre1986), Vol. 94, No.2, p.215.

Rahman, A. A. (2014),"A Longitudinal Study of the Readability of the Chairman's Narratives in Corporate Reports: Malaysian Evidence. World Academy of Science, Engineering and Technology, International Journal of Social, Behavioral, Educational, Economic, Business and Industrial Engineering, Vol.8,No.7, pp.2044-2051.

Richards, G., \& van Staden, C. (2015)" The readability impact of international financial reporting standards", Pacific Accounting Review, Vol.27, No.3, pp. 282-303.

Sattari, S., Pitt, L.F. and Caruana, A.(2011),"How readable are mission statements? An exploratory study", Corporate Communications: An International Journal. Vol.16,No.4, pp.282-292.

Schroeder, N. and Gibson, C.(1992)" Are summary annual reports successful?", Accounting Horizons, Vol.6,No.2, p.28.

Smith, M. and Taffler, R., (1992),"Readability and understandability: Different measures of the textual complexity of accounting narrative", Accounting, Auditing \& Accountability Journal, Vol.5, No.4,pp.

Subramanian, R., Insley, R.G. and Blackwell, R.D. (1993) ,"Performance and readability: A comparison of annual reports of profitable and unprofitable corporations ", The Journal of Business Communication, Vol . 30, No. 1, pp. 49-61.

Taylor, W. L. (1953)," Cloze procedure: A new tool for measuring

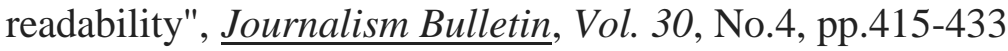




\section{Table (1):descriptive statistics of chairman's letter}

\begin{tabular}{|c|c|c|c|c|c|c|c|c|c|c|c|c|c|c|c|}
\hline \multirow{2}{*}{ Variables } & \multicolumn{5}{|c|}{ Panel A: total sample } & \multicolumn{5}{|c|}{ Panel B:financial firms } & \multicolumn{5}{|c|}{ Panel C: non-financial firms } \\
\hline & $\mathrm{N}$ & Min. & Max. & $\mathrm{M}$ & SD & $\mathrm{N}$ & Min. & Max. & $\mathrm{M}$ & SD & $\mathrm{N}$ & Min. & Max. & $\mathrm{M}$ & SD \\
\hline Number of sentences & 9 & 3.0 & 179.0 & 47.1 & 53.5 & 4 & 37.0 & 179.0 & 83.5 & 65.5 & 5 & 3.0 & 30.0 & 18.0 & 10.9 \\
\hline Words per sentences & 9 & 4.0 & 31.6 & 20.2 & 10.2 & 4 & 4.0 & 28.0 & 12.6 & 10.6 & 5 & 21.1 & 31.6 & 26.2 & 4.5 \\
\hline Percent of difficult words & 9 & 0.2 & 21.4 & 2.6 & 7.1 & 4 & 0.2 & 21.4 & 5.5 & 10.5 & 5 & 0.2 & 0.3 & 0.2 & 0.0 \\
\hline Flesch reading ease & 9 & 20.3 & 53.6 & 36.1 & 11.3 & 4 & 33.1 & 53.6 & 44.8 & 10.1 & 5 & 20.3 & 37.9 & 29.1 & 6.4 \\
\hline SMOG grade & 5 & 8.4 & 17.1 & 12.9 & 3.7 & 4 & 8.4 & 17.1 & 12.1 & 3.6 & 1 & 16.3 & 16.3 & 16.3 & 0.0 \\
\hline Dale- Chall score & 9 & 8.8 & 11.1 & 10.1 & 0.7 & 4 & 8.8 & 10.5 & 9.8 & 0.7 & 5 & 9.6 & 11.1 & 10.4 & 0.6 \\
\hline
\end{tabular}

Abbreviations which are N, Min., Max., M and SD refer to number of firms, minimum value, maximum value, mean and standard deviation respectively per each variable. 


\section{Table (2):descriptive statistics of social responsibility narrative disclosure}

\begin{tabular}{|c|c|c|c|c|c|c|c|c|c|c|c|c|c|c|c|}
\hline \multirow{2}{*}{ Variables } & \multicolumn{5}{|c|}{ Panel D: total sample } & \multicolumn{5}{|c|}{ Panel E:financial firms } & \multicolumn{5}{|c|}{ Panel $F$ : non-financial firms } \\
\hline & $\mathrm{N}$ & Min. & Max. & $\mathrm{M}$ & SD & $\mathrm{N}$ & Min. & Max. & $\mathrm{M}$ & SD & $\mathrm{N}$ & Min. & Max. & $\mathrm{M}$ & $\mathrm{SD}$ \\
\hline Number of sentences & 9 & 3.0 & 318.0 & 52.8 & 101.4 & 4 & 10.0 & 318.0 & 101.0 & 146.1 & 5 & 3.0 & 49.0 & 14.2 & 19.7 \\
\hline Words per sentences & 9 & 5.2 & 31.0 & 17.4 & 9.6 & 4 & 5.3 & 28.4 & 13.3 & 10.5 & 5 & 8.9 & 31.0 & 20.6 & 8.6 \\
\hline Characters per word & 9 & 5.3 & 6.0 & 5.7 & 0.3 & 4 & 5.4 & 6.0 & 5.7 & 0.3 & 5 & 5.3 & 6.0 & 5.6 & 0.3 \\
\hline Percent of difficult words & 9 & 0.3 & 0.3 & 0.3 & 0.0 & 4 & 0.2 & 0.3 & .29 & 0.0 & 5 & 0.2 & 0.3 & .29 & 0.02 \\
\hline Flesch reading ease & 9 & 4.7 & 36.2 & 22.0 & 10.4 & 4 & 20.3 & 36.2 & 27.7 & 8.0 & 5 & 4.6 & 27.9 & 17.5 & 10.5 \\
\hline Gunning fog level scale & 9 & 15.2 & 24.4 & 18.8 & 3.1 & 4 & 15.2 & 21.2 & 17.4 & 2.6 & 5 & 15. & 24.4 & 19.9 & 3.2 \\
\hline Flesch - Kincaid grade level & 9 & 10.4 & 19.7 & 14.6 & 3.4 & 4 & 10.4 & 17.3 & 12.9 & 3.0 & 5 & 11.9 & 19.7 & 15.9 & 3.3 \\
\hline SMOG grade & 3 & 11.5 & 12.5 & 12.1 & 0.5 & 2 & 11.5 & 12.5 & 12.0 & 0.7 & 1 & 12.4 & 12.4 & 12.4 & 0.0 \\
\hline Dale- Chall score & 9 & 9.7 & 12.8 & 11.1 & 0.8 & 4 & 9.7 & 11.4 & 10.7 & 0.7 & 5 & 10.4 & 12.9 & 11.5 & 0.9 \\
\hline
\end{tabular}

Note: Abbreviations which are N, Min., Max., M and SD refer to number of firms, minimum value, maximum value, mean and standard deviation respectively per each variable. 
Table (3) :Mann-Whitney results of chairman's letter between financial and nonfinancial firms

\begin{tabular}{|c|c|c|c|c|c|}
\hline Variables & Sector & $\mathrm{N}$ & $\begin{array}{l}\text { Mean } \\
\text { Rank }\end{array}$ & $\begin{array}{l}\text { Sum of } \\
\text { Ranks }\end{array}$ & Sig. \\
\hline \multirow{2}{*}{ Number of sentences } & 1 & 4 & 7.50 & 30.00 & \multirow{2}{*}{0.014} \\
\hline & 2 & 5 & 3.00 & 15.00 & \\
\hline \multirow{2}{*}{ Words per sentences } & 1 & 4 & 3.25 & 13.00 & \multirow{2}{*}{0.086} \\
\hline & 2 & 5 & 6.40 & 32.00 & \\
\hline \multirow{2}{*}{ Characters per word } & 1 & 4 & 4.25 & 17.00 & \multirow{2}{*}{0.462} \\
\hline & 2 & 5 & 5.60 & 28.00 & \\
\hline \multirow{2}{*}{ Percent of difficult words } & 1 & 4 & 5.75 & 23.00 & \multirow{2}{*}{0.462} \\
\hline & 2 & 5 & 4.40 & 22.00 & \\
\hline \multirow{2}{*}{ Flesch reading ease } & 1 & 4 & 7.25 & 29.00 & \multirow{2}{*}{0.027} \\
\hline & 2 & 5 & 3.20 & 16.00 & \\
\hline \multirow{2}{*}{ Gunning fog level scale } & 1 & 4 & 3.25 & 13.00 & \multirow{2}{*}{0.086} \\
\hline & 2 & 5 & 6.40 & 32.00 & \\
\hline \multirow{2}{*}{ Flesch - Kincaid grade level } & 1 & 4 & 3.25 & 13.00 & \multirow{2}{*}{.086} \\
\hline & 2 & 5 & 6.40 & 32.00 & \\
\hline \multirow{2}{*}{ SMOG grade } & 1 & 4 & 2.75 & 11.00 & \multirow{2}{*}{.480} \\
\hline & 2 & 1 & 4.00 & 4.00 & \\
\hline \multirow{2}{*}{ Dale- Chall score } & 1 & 4 & 3.75 & 15.00 & \multirow{2}{*}{.221} \\
\hline & 2 & 5 & 6.00 & 30.00 & \\
\hline
\end{tabular}

Note: 1 and 2 refer to the sectors financial and non-financial firms individually. 
Table (4) : Mann-Whitney results of responsibility disclosure between financial and non-financial firms

\begin{tabular}{|c|c|c|c|c|c|}
\hline Variables & Sector & $\mathrm{N}$ & $\begin{array}{l}\text { Mean } \\
\text { Rank }\end{array}$ & $\begin{array}{c}\text { Sum of } \\
\text { Ranks }\end{array}$ & Sig. \\
\hline \multirow{2}{*}{ Number of sentences } & 1 & 4 & 6.8 & 27.0 & \multirow{2}{*}{.085} \\
\hline & 2 & 5 & 3.6 & 18.0 & \\
\hline \multirow{2}{*}{ Words per sentences } & 1 & 4 & 3.8 & 15.0 & \multirow{2}{*}{0.221} \\
\hline & 2 & 5 & 6.0 & 30.0 & \\
\hline \multirow{2}{*}{ Characters per word } & 1 & 4 & 5.3 & 21.0 & \multirow{2}{*}{0.806} \\
\hline & 2 & 5 & 4.8 & 24.0 & \\
\hline \multirow{2}{*}{ Percent of difficult words } & 1 & 4 & 5.3 & 21.0 & \multirow{2}{*}{0.806} \\
\hline & 2 & 5 & 4.8 & 24.0 & \\
\hline \multirow{2}{*}{ Flesch reading ease } & 1 & 4 & 6.5 & 26.0 & \multirow{2}{*}{0.142} \\
\hline & 2 & 5 & 3.8 & 19.0 & \\
\hline \multirow{2}{*}{ Gunning fog level scale } & 1 & 4 & 4.0 & 16.0 & \multirow{2}{*}{0.327} \\
\hline & 2 & 5 & 5.8 & 29.0 & \\
\hline \multirow{2}{*}{ Flesch - Kincaid grade level } & 1 & 4 & 3.5 & 14.0 & \multirow{2}{*}{0.142} \\
\hline & 2 & 5 & 6.2 & 31.0 & \\
\hline \multirow[t]{2}{*}{ SMOG grade } & 1 & 2 & 2.0 & 4.0 & \multirow{2}{*}{1.00} \\
\hline & 2 & 1 & 2.0 & 2.0 & \\
\hline \multirow{2}{*}{ Dale- Chall score } & 1 & 4 & 3.8 & 15.0 & \multirow{2}{*}{0.221} \\
\hline & 2 & 5 & 6.0 & 30.0 & \\
\hline
\end{tabular}

Note: 1 and 2 refer to the sectors financial and non-financial firms individually. 
Table (5): correlation coefficient of readability measures related to chairman's letter

\begin{tabular}{|c|l|c|c|c|c|c|c|c|c|c|}
\hline & & $(1)$ & $(2)$ & $(3)$ & $(4)$ & $(5)$ & $(6)$ & $(7)$ & $(8)$ & $(9)$ \\
\hline$(1)$ & Number of sentences & 1 & & & & & & & & \\
\hline$(2)$ & Words per sentences & $-.794^{*}$ & 1 & & & & & & & \\
\hline$(3)$ & Characters per word & -.018 & -.067 & 1 & & & & & & \\
\hline$(4)$ & Percent of difficult words & $.925^{* *}$ & -.595 & -.101 & 1 & & & & & \\
\hline$(5)$ & Flesch reading ease & $.667^{*}$ & $-.857^{* *}$ & -.379 & .556 & 1 & & & & \\
\hline$(6)$ & Gunning fog level scale & $-.759^{*}$ & $.962^{* *}$ & .114 & -.617 & $-.951^{* *}$ & 1 & & & \\
\hline$(7)$ & Flesch - Kincaid grade level & $-.772^{*}$ & $.979^{* *}$ & .108 & -.600 & $-.944^{* *}$ & $.992^{* *}$ & 1 & & \\
\hline$(8)$ & SMOG grade & -.811 & $.985^{* *}$ & -.180 & -.683 & -.861 & $.986^{* *}$ & $.986^{* *}$ & 1 & \\
\hline$(9)$ & Dale- Chall score & -.081 & .221 & $.675^{*}$ & -.090 & -.648 & .411 & .398 & .350 & 1 \\
\hline
\end{tabular}

*. Correlation is significant at the 0.05 level (2-tailed).

**. Correlation is significant at the 0.01 level (2-tailed). 
Table (6): correlation coefficient of readability measures related to responsibility disclosure

\begin{tabular}{|c|l|r|r|r|r|r|r|r|c|c|}
\hline & & $(1)$ & $(2)$ & $(3)$ & $(4)$ & \multicolumn{1}{c|}{$(5)$} & $(6)$ & $(7)$ & $(8)$ & $(9)$ \\
\hline$(1)$ & Number of sentences & 1 & & & & & & & & \\
\hline$(2)$ & Words per sentences & -.551 & 1 & & & & & & & \\
\hline$(3)$ & Characters per word & .230 & $-.727^{*}$ & 1 & & & & & & \\
\hline$(4)$ & Percent of difficult words & .345 & $-.679^{*}$ & .659 & 1 & & & & & \\
\hline$(5)$ & Flesch reading ease & .456 & -.585 & -.011 & .086 & 1 & & & & \\
\hline$(6)$ & Gunning fog level scale & -.565 & $.950^{* *}$ & -.612 & -.432 & $-.712^{*}$ & 1 & & & \\
\hline$(7)$ & Flesch - Kincaid grade level & -.585 & $.924^{* *}$ & -.474 & -.484 & $-.847^{* *}$ & $.956^{* *}$ & 1 & & \\
\hline$(8)$ & SMOG grade & -.991 & -.064 & .916 & .126 & -.863 & .696 & .945 & 1 & \\
\hline$(9)$ & Dale- Chall score & -.053 & .077 & .545 & .426 & $-.735^{*}$ & .267 & .378 & .296 & 1 \\
\hline
\end{tabular}

*. Correlation is significant at the 0.05 level (2-tailed).

**. Correlation is significant at the 0.01 level (2-tailed). 